Madrygal. Revista de Estudios Gallegos

ISSN: 1138-9664

\title{
O relato histórico no mito: Enrique Líster e a batalla das palabras
}

\author{
José Galán Ortega ${ }^{1}$
}

Recibido: 29 de outubro de 2019 / Aceptado: 17 de xuño de 2020

Resumo. Este artigo pretende explorar as conexións existentes entre o relato da experiencia de guerra, a memoria do protagonista dos feitos bélicos narrados e o plano cultural das emocións proxectadas nos textos e noutros documentos autobiográficos (medo, compaixón, orgullo...) legados por Enrique Líster Forján, xefe militar e dirixente comunista galego. A metodoloxía escollida para este traballo permite un achegamento dende a historia cultural aos diversos contextos da escritura e aos elementos máis importantes da interpretación trazada sobre conceptos como camaradería e masculinidade por un militante comunista comprometido na construción dun mundo novo, no bloqueo do avance fascista sobre España e Europa e, máis tarde, no derrocamento da ditadura franquista. Unha loita continua levada a cabo ata o final por medio da palabra e da transformación da derrota sufrida fronte a Franco e os seus aliados nazi-fascistas nun relato mobilizador que manexa a épica de forma selectiva e como estratexia para outorgarlle ao suxeito principal do seu discurso, o pobo, un papel privilexiado na rexeneración do seu destino histórico.

Palabras chave: Enrique Líster; memoria; experiencia de guerra; emocións; camaradería; masculinidades.

\section{[es] El relato histórico en el mito: Enrique Líster y la batalla de las palabras}

Resumen. Este artículo pretende explorar las conexiones existentes entre el relato de la experiencia de guerra, la memoria del protagonista de los hechos bélicos narrados y el plano cultural de las emociones proyectadas en los textos y en otros documentos autobiográficos (miedo, compasión, orgullo...) legados por Enrique Líster Forján, jefe militar y dirigente comunista gallego. La metodología elegida para este trabajo permite un acercamiento desde la historia cultural a los distintos contextos de la escritura y a los elementos más importantes de la interpretación trazada sobre conceptos como camaradería o masculinidad por un militante comunista comprometido en la construcción de un mundo nuevo, en el bloqueo del avance fascista sobre España y Europa y, más tarde, en el derrocamiento de la dictadura franquista. Una lucha continua llevada a cabo hasta el final por medio de la palabra y de la transformación de la derrota sufrida frente a Franco y sus aliados nazi-fascistas en un relato movilizador que maneja la épica de forma selectiva y como estrategia para otorgarle al sujeto principal de su discurso, el pueblo, un papel privilegiado en la regeneración de su destino histórico.

Palabras clave: Enrique Líster; memoria; experiencia de guerra; emociones; camaradería; masculinidades.

\section{[en] The Historical Account in the Myth: Enrique Líster and the Battle of Words}

\begin{abstract}
This article intends to explore the existing conections among the accounts of war experience, the memory of the protagonist of the narrated war events and the cultural dimension of the emotions projected in the texts and other autobiographical documents (fear, compasión, pride...) created by Enrique Líster Forján, the Galician military and communist leader. The methodology chosen for this work applies an approach from cultural history to the different contexts of writing and the most important elements of the interpretation focused on concepts such as comradeship and masculinity by a comunist militant committed to the construction of a new world, to stop the fascist advance on Spain and Europe and, later on, in the overthrowal of the francoist dictatorship. A continuous fight carried out until the end by discursive means, and the transformation of the defeat suffered against Franco and his nazi-fascist allies into a mobilizing story that handles the epic in a selective way and as a strategy to grant the people a privileged role in the regeneration of their historical destiny.
\end{abstract}

Keywords: Enrique Líster; Memory; Experience of War; Emotions; Comradeship; Masculinities.

1 Doutor en Historia Contemporánea pola Universidad Complutense de Madrid.

Correo-e: josegalanortega@gmail.com; https://orcid.org/0000-0001-9395-517X. 
Sumario. 1. Memoria, experiencia de guerra e emocións. 2. O contexto da escritura. 3. Experiencia bélica, masculinidades e camaradería. 4. Repertorios emocionais ou a memoria fronte ao espello. 5. Conclusións. 6. Referencias bibliográficas.

Como citar: Galán Ortega, J. (2020): “O relato histórico no mito: Enrique Líster e a batalla das palabras”, en $\mathrm{Ma}$ drygal. Revista de Estudios Gallegos 23 Núm. Especial, pp. 185-201.

\section{Memoria, experiencia de guerra e emocións}

A figura de Enrique Líster define perfectamente a complexidade dunha época que oscilou entre a grandeza humana, co selo da resiliencia e o sacrificio polos ideais emancipadores, e a negrura social e política, nun contexto onde a experiencia humana (tamén a súa épica) acadaba unha intensidade crítica: o exilio, a cadea, a morte e o sufrimento colectivo no sentido máis amplo.

Como un dos mitos sobranceiros legados polo comunismo español á causa da República e do exilio español do 39, a memoria de Líster revela a conciencia igualitaria e internacionalista xunto á loita pola supervivencia da clase traballadora e o emprego da forza militar de autodefensa como elementos dunha identidade adaptada a un determinado tempo histórico, á marxe do valor específico do fenómeno bélico na resolución de conflitos nacionais e políticos.

Porén, o sentido principal deste artigo reside no achegamento á memoria e representación da experiencia de guerra de Enrique Líster, á lembranza do conflito bélico e á súa propia participación no combate e no seu mundo referencial, simbólico e político. O obxecto prioritario ha transcender, pois, o pulo estrito dos acontecementos autobiográficos narrados e vaise centrar na experiencia de guerra como eixo cultural do recordo. Unha experiencia de guerra que non é precisamente allea á loita que o militar e dirixente político galego emprendeu décadas despois de rematar a guerra civil: unha loita narrativa na que o territorio a conquerir sería o relato e o seu reflexo na toma de conciencia de novos e vellos lectores.

Aínda que a escritura dunha historia global ou omnicomprensiva da experiencia de guerra semella, en principio, un obxectivo certamente complicado - cantos relatos non se escribiron ou fican perdidos ou agochados, cantos contextos globais deben ser descifrados-, a pescuda sobre os relatos das experiencias individuais ou colectivas leva sempre implícito o selo inconsciente da fascinación provocada pola guerra como realidade que traspasa calquera umbral cultural ou histórico. Partindo pois dunha perspectiva pragmática, a aproximación á rememoración da vivencia individual adquire unha importancia crecente para a comprensión do feito bélico como fenómeno complexo, especialmente na súa dimensión humana, xa que permite captar a especificidade real das memorias persoais como relato primario a inserir, se cabe, nas dinámicas colectivas do recordo. Segundo unha metodoloxía máis ambiciosa, compatíbel coa tensión existente entre os marcos das experiencias individuais, colectivas e globais (máis axustadas a abstraccións ou arquetipos), hai que considerar que

[...] if all the personal recollections of all the soldiers in the world's wars were gathered toguether, they would tell one huge story of men at war-changing, as armies and weapons and battelfields changed, but still a whole coherent story. Such an entire tale can never exist: the men who could tell it are mostly dead, and while they lived they were inarticulate, or simply distracted by life, so that their wars were left unrecorded. Nevertheless, that notional tale is my subject: what happened in war, one man at a time; who the men where, who told war's separate stories and what their stories tell us (and don't tell us) about war; and how the experience of war has changed in our century, as one war has followed another. (Hynes 1998: 22)

Inspirándonos na perspectiva humanista que subxace ao marco metodolóxico proposto por este autor, poderíase entón considerar a posibilidade da configuración dunha historia da experiencia de guerra -ou, máis polo miúdo, da súa memoria- que aspire no fundamental a recoller e singularizar, a partir dunha contextualización ben dirixida e artellada, todas as narrativas persoais para enfialas deseguido nun relato global plenamente inclusivo. Neste esquema, a experiencia de guerra de Enrique Líster vaise examinar, con vocación de síntese, como a dun ser humano (un actor político) que enfronta a natureza e os significados da guerra (con todo o que iso implica) e experimenta intensas emocións sociais ao longo dunha cronoloxía inestábel, deixando nun segundo plano a dimensión de mito político que a miúdo agocha outros ángulos da súa figura e traxectoria. Por outro lado, non convén esquecer que Líster combateu sempre con e contra as palabras, mergullado nunha linguaxe tinguida de emocións subliñadas ou contidas, segundo o caso, pero sempre latexantes na hora da memoria e da escritura. 
Debido á obrigada brevidade deste traballo, semella un reto o tratamento da memoria da experiencia de guerra dende unha perspectiva coherente coas pautas propostas pola nova historia das emocións e a nova historia cultural. As emocións convértense agora nun vencello forte entre os individuos e o mundo, asumindo a función representada pola linguaxe no xiro lingüístico para a análise de procesos históricos e actos de memoria individuais e colectivos. Neste caso, non se trata de acceder en profundidade a estados psicolóxicos ou cerebrais, senón de pescudar nas emocións culturalmente significativas, as que transcenden o mundo interno para se visibilizar en formas narrativas ou simbólicas e adquirir sentidos diversos segundo os contextos históricos e políticos nos que xorden ou, mellor dito, se constitúen. Dese xeito, cando se fale de medo, odio ou compaixón non se aludirá a sentimentos, afectos ou emocións provistos dunha entidade independente ou autónoma -estes conceptos serán aquí intercambiábeis-, senón como construtos vencellados a suxeitos ou grupos activos, nos planos da acción ou da memoria, baixo determinadas conxunturas sociopolíticas. Noutras palabras, a trabe deste esquema provisional implicaría achegarse ás experiencias que orixinaron as emocións e as representacións ou expresións xeradas por estas (Moscoso 2011: 16-18).

Este enfoque cultural ábrese, no entanto, a un certo grao de contradición e polo tanto non vai impedir a influencia de teorías que dende a neurociencia ou a psicoloxía cognitiva sinalan a función esencial que as emocións teñen no acto (actos) de memoria e subliñan a estreita relación existente entre o universo emocional e os recordos, pois os recordos envoltos en emocións intensas poden reforzarse ou tamén debilitarse (Ruiz Vargas 2010: 365), vencello hoxe similar ao estabelecido entre o pensamento racional e a emoción ${ }^{2}$.

Un bo punto de referencia para os historiadores interesados neste obxecto de estudo estaría arredor dunha teoría orientada á interpretación social das emocións: estas ocorrerían entre individuos e non soamente en cada individuo (Ledoux 1999: 26). Porén, neste punto cómpre ter de conta a advertencia de
Jan Pampler (2014: 28-29) sobre a asimilación do impacto da neurociencia afectiva sen unha valoración meditada de determinadas metodoloxías (lastradas polo peso do principio de replicabilidade) ou certas condicións epistemolóxicas (a lóxica binaria verdadeiro/falso) que poderían distorcer os enfoques historiográficos máis rigorosos.

En calquera caso, esas emocións que emerxen no acto de memoria e escritura non son as mesmas que se viviron en tempo real no propio combate, pois levan de seu un marcado contido racional, unha lóxica de pensamento que, por outra banda, se mostra coherente co contexto sociopolítico preciso da narrativa experiencial de guerra, do momento histórico no que o suxeito (neste caso Líster) rememora, reflexiona e escribe ou plasma os seus recordos no medio escollido. Esta hipótese de traballo formula unha liña provisional de investigación que precisa dun maior espazo para profundar nela, pero non por iso fica á marxe das liñas que definen a nova historia cultural.

Como tantas figuras históricas do seu tempo e da súa relevancia, elevadas á categoría de mito de modo inmediato, Enrique Líster debía xestionar con mestría lembranzas e esquecementos - unha pauta defensiva á hora de facer balances finais, persoais e colectivos-, canto menos tentar de artellar un territorio de escritura onde non se visen as sombras máis comprometedoras, algo lóxico e certamente ensaiado ao seu modo. Obviamente, o político e militar galego tivo unha longa e complexa traxectoria, inserida na dinámica histórica convulsa que caracterizou o século XX. Desenvolveu diversos roles sociais, políticos e profesionais. Foi canteiro, campesiño, emigrante económico en Cuba, fuxido á URSS por motivos políticos a principios dos trinta -traballou de barreneiro na construción do metro de Moscú, en condicións moi penosas, como el mesmo recoñecería máis tarde-, miliciano, xefe militar, exiliado, instrutor de varios exércitos -soviético e iugoslavo- e, finalmente, dirixente político enfrontado á dirección do PCE liderado por Carrillo e a nova orientación eurocomunista.

Mais, por riba de todo, foi un militante comunista galego que nunca deixou de loitar porque en realidade nin aceptaba nin concibía

\footnotetext{
Para a interacción entre neurobioloxía, emocións e cultura, véxase Damasio 2006. Para acadar unha impresión preliminar dun modelo de equilibrio entre emocións e razoamento, é dicir, entre distintos procesos mentais, remitimos a Morgado 2007: 12-15. A interpretación cultural das emocións en Lavanyi 2016.
} 
a derrota como escusa ou argumento para a rendición ou o abandono das obrigas persoais e colectivas, na súa visión épica da historia protagonizada sempre polo suxeito popular e a súa dignidade.

Líster afirmou que non pretendera nunca exercer de historiador, senón propoñer a súa particular visión da época e os feitos históricos e políticos vividos. Porén, non queda claro a que modelo de historiador se estaba a referir ao rexeitar unha función da que non renegara abertamente nin na preparación de Guerra $y$ revolución en España... -tarefa para a que foi requirido polo partido- (Juan Carlos Rueda 2018: 78), nin moito menos da propia redacción de Nuestra guerra (1966), cuxo subtítulo (Aportaciones a una Historia de la Guerra Nacional Revolucionaria del Pueblo Español...) suxire unha intención máis obxectiva ${ }^{3}$. Certo é tamén que o militar e político galego afirma o seu respecto pola historiografía como disciplina obxectiva, unha estima que debía gardar un equilibrio complexo coa tendencia dos autores-protagonistas a xustificar as súas propias accións e proxectar responsabilidades sen mesura, encrucillada na que sae relativamente airoso ao recoñecer erros e contemplar as trampas da perspectiva, en especial -e obviamente con máis énfase- da temporal.

En todo caso, a narrativa de Líster non vai ser examinada nestas páxinas en función da súa capacidade de reflectir a realidade histórica (un fin que, por certo, o militar galego quere cadrar coa súa versión de determinadas situacións). Esta premisa non implica a afirmación da autorreferencialidade absoluta ou obrigada dos textos memorialísticos ou autobiográficos ou a negación do seu valor como fonte histórica.

\section{2. $O$ contexto da escritura}

Tanto na primeira edición do que podemos considerar as súas memorias, como na publicada poucos anos despois da morte de Franco, Enrique Líster citaba as peticións de camaradas e amigos e a necesidade de refugar as versións nesgadas do acontecido na guerra civil (autoxustificación fronte a un mito negativo asociado á figura do militar galego) entre as razóns que o levaron á escritura das súas memorias.

Así pois, recoñecía Líster que tomou a decisión de escribir as súas lembranzas baixo a presión dos "deseos expresados por numerosos camaradas y otras personas que consideran puede ayudar a la lucha el relato de las experiencias de un militante que ha vivido un largo periodo de la historia del movimiento comunista español" (1977: 7). Unha decisión tamén informada dunha obriga moral e pedagóxica de educar tamén a mocidade no coñecemento da historia do comunismo español, misión que requiría da adopción dunha postura especial de honestidade por parte do autor. A pedagoxía explicitada no limiar á primeira edición (1966) -publicada nun momento político diferente, como é obvio- difería un tanto no seu obxecto e menos nos destinatarios. Nese lugar, Líster confesaba que as súas memorias (segundo os textos, a súa biografía estaría monopolizada pola guerra e o Partido) tiñan tanto a intención de acordar dos que caeron na guerra ou sobreviviron a ela facéndose dignos dos sacrificados, como o desexo recorrente de informar os fillos dos que fixeron a guerra en ambos bandos e mais a todos os comprometidos en superar as secuelas do conflito. De servir minimamente este primeiro libro para os fins citados, Líster consideraríao "como una batalla ganada al enemigo común" (1966: 10).

Ademais, neste punto vese nidiamente a idea da loita continua canalizada agora por medio da escritura e o seu valor resiliente e persuasivo, dentro do marco histórico dunha longa guerra de papel que chegaría ata o noso presente con resultados incertos (Pablo Sánchez León e Jesús Izquierdo 2017: 90-93). Un argumento -en relación ao caso de Líster- perfectamente coherente coa traxectoria dun home totalmente identificado co universo político comunista, que nunca dubidaría en autodefinirse como un combatiente, un luchador (véxase o subtítulo das edicións das súas

\footnotetext{
Nuestra guerra. Aportaciones para una Historia de la Guerra Nacional Revolucionaria del Pueblo Español 19361939 foi editada en París por Editions de la Librairie du Globe, dentro da célebre colección Ebro. Tras a morte do ditador, Líster publicou unha nova versión do libro, co título de Memorias de un luchador. 1. Los primeros combates (Madrid, 1977) - proxectado como primeira entrega dunha serie que non foi completada, aínda que Basta (1970) e Así destruyó Carrillo el PCE (1983) fixeron por cubrir o oco creado-, na que en esencia modificou só o prefacio, dirixido agora expresamente "al lector". Pola súa banda, Ediciones Silente publicou unha nova edición do libro en 2007, engadindo agora un prefacio asinado por Pedro A. García Bilbao.
} 
memorias dende 1977), un militante revolucionario en maiúsculas. A conciencia posuída do sacrificio real por unha causa esparexíase polos distintos espazos de privacidade e sociabilidade transitados:

Como podrá verse a lo largo de lo que se relata en estos dos tomos, puede ser que ciertas gentes consideren que en mis memorias hay demasiado comunismo. Por comunistas fueron fusilados en 1936 dos de mis hermanos y perseguidos los demás. Mi esposa es comunista desde los diecisiete años y comunistas son nuestros hijos. La mayor parte de nuestras amistades son comunistas, y esto sin sectarismos, pues tengo buenos amigos que no son comunistas y sin duda no lo serán jamás, lo que es su perfecto derecho. (Líster 1977: 9)

Unha das claves desta identidade ideolóxica tan forte áchase principalmente na mística e significados que a cultura política comunista confire ao Partido, unha auténtica alma colectiva, unha tipoloxía especial de comunidade ou familia onde a solidariedade e a fraternidade precisan dun sentido especial de pertenza e lealdade extremas integrado na herdanza cultural dos militantes (Francisco Erice 2009: 143-146). E por esa mesma vía Líster (como todos os líderes do Partido) tiña que afrontar finalmente a responsabilidade autoimposta do seu liderado -independentemente de ficar ou non na estrutura do PCE-, tamén o orgullo da fidelidade compartida á organización e ao movemento internacionalista, ou a dor interna polas traizóns a determinadas doutrinas, estratexias e compañeiros lexitimadas por obrigas políticas e morais. O factor subxacente de producir lecturas ou interpretacións rigoristas da realidade baixo o peso de determinados contextos históricos -convén non esquecer isoou de criterios disciplinarios severos, axuda á comprensión do fluxo das perspectivas psicolóxicas que se suceden no tratamento da experiencia de guerra.

Informar as xeracións máis novas verbo da guerra civil, sempre a partir de determinadas premisas teóricas, pódese converter nun modo de subverter a lóxica da propia derrota: malia ser esta asumida como inevitábel dada a magnitude do apoio fascista a Franco, nin socavaría o movemento internacionalista de forte influencia soviética nin afectaría substancialmente a causa comunista.

O corpo central de ambos libros xira arredor da guerra civil e ao papel de Líster e os comunistas nela, presentando algunhas diferenzas que serven para unha contextualización máis precisa dos textos, exercicio que o mesmo autor considera esencial para a comprensión cabal da súa obra e traxectoria militar e política. A de 1977 ampliaría e corrixiría algúns puntos importantes, relativos especialmente á crítica do papel na guerra dalgúns líderes do Partido (e non só, ampliándose o foco a esquerda e dereita), tarefa aprazada na primeira edición (1966) por mor dunha censura autoimposta debido a que o ditador e a ditadura aínda estaban vivos fisicamente, como recoñece o autor no comezo da obra.

Como queda dito, o conflito central que vai decidir o abandono de Líster do PCE xa se albisca no brevísimo texto limiar do 66, codificado na advertencia feita polo autor en referencia aos límites impostos no discurso memorístico pola persistencia da ditadura e da propia actividade opositora do PCE. Límites que farían xurdir polémicas contraproducentes nun presente escuro, incómodo, tinguido durante a transición dunha retórica máis autocompracente e agresiva co oficialismo representado por Carrillo e o pasado roubado polos oportunistas enfrontados á ortodoxia soviética. Esta segunda edición das súas memorias que, como se dixo antes, foi publicada en Madrid en 1977, amosaría, pois, xa sen os códigos simbólicos e lingüísticos utilizados tradicionalmente no discurso comunista para disfrazar a crítica ou a disensión, unha memoria marcada pola confrontación co silencio adoptado pola esquerda transixente co pacto asinado polas forzas democráticas e o aparato do franquismo. Un pacto facilitador dunha reconciliación que Líster rexeita por falsa, ao estar deseñada en favor do aparato e as estruturas institucionais franquistas.

Á marxe das lecturas políticas e históricas formuladas, as claves de memoria relativas á experiencia de guerra ficaban case inalterábeis e revelaban un vínculo forte coa dimensión emocional e identitaria do suxeito. Vínculo coherente cunha bagaxe ideolóxica, a do proletariado, que abranguía as arelas de solidariedade e fraternidade universal que contrapesaban as pegadas deixadas pola ditadura franquista na estrutura sociopolítica do país. O caso de Enrique Líster constitúe por extensión o de tantos homes e mulleres abocados de modo azaroso á vida militar e, por tanto, á formación ritual, ideolóxica e técnica para a perpetración da violencia (cunha motivación pretendidamente autodefensiva), no proceso bélico contemplado, dende algúns sectores, como un escenario 
inevitábel dentro dos procesos de polarización política acontecidos durante a II República.

A función desenvolvida durante o período republicano polo militante comunista galego como instrutor das MAOC, ou enlace dunha misión antimilitarista en varios cuarteis madrileños, implicou un arriscado labor de axitación informativa desprovista dun sentido estritamente pacifista. A estratexia antimilitarista marcada pola dirección do PCE non rexeitaba realmente a formación militar da xuventude e dos obreiros, senón que se opuña á orde social e xerárquica militarista máis ao papel institucional do exército (Víctor Santidrián 2018: 434). Neste punto, as memorias de Líster e doutros protagonistas da fase embrionaria das milicias tenden a subliñar o seu carácter autodefensivo antes da guerra civil, remarcando os labores de protección de manifestacións e actos públicos atribuídos ás MAOC perante a ameaza dos pistoleiros falanxistas, funcións ampliadas despois a misións de vixilancia ante a inminencia do golpe de estado. Unha tendencia a acoutar actos e actores individuais ou grupais que muda cando o foco se pon sobre $o$ acontecido na guerra civil e, máis especificamente, nas operacións en que van intervir as súas unidades, período no que a guerra como concepto e realidade ha cobrar novos significados e construír unha épica duradeira.

Malia que o obxecto principal deste artigo non é a pescuda sobre o grao de verosimilitude dos textos memorialísticos citados, si que se pode inferir o peso do estigma histórico manexado pola historiografía franquista (agora en mans do novo revisionismo) verbo da estratexia comunista como prólogo dunha revolución inspirada no modelo soviético. É por iso que Líster, Modesto ou Tagueña souberon sortear nos seus relatos algúns aspectos sensíbeis da historia do PCE e outros grupos de esquerda nos anos previos á guerra civil, aínda que en realidade a política e a actuación dos comunistas durante a etapa republicana non fixeran por artellar ningún proxecto revolucionario, nin moito menos participar en conflitos armados que puidesen xerar unha experiencia de guerra real, alén das expresións de violencia condicionada polos sucesos de outubro do 34 .

O propio concepto de experiencia de guerra sería, por tanto, de difícil aplicación no contexto do entrecruzamento dos planos da vivencia e recordo, cinguidos aquí á complexa pero ben delimitada conflitividade sociopolítica da II República. En todo caso, o fenómeno das violencias políticas cristalizadas no período republicano non pertence a un escenario prebélico ou de guerra propiamente -a súa tipoloxía e cronoloxía nunca se traduciría nunha frecha temporal de traxectoria predeterminada cara á guerra civil-, como algúns autores pretenden, senón que esta conflitividade acontece nun réxime democrático perfectamente lexítimo nas coordenadas do tempo histórico de entreguerras.

\section{Experiencia bélica, masculinidades e ca- maradería}

Como vive e lembra a guerra un loitador que se atopa a si mesmo nun presente eterno, nun plano de escritura completamente vivo e dinámico? A brevidade deste artigo non permite profundar no marco interpretativo e teórico todo o desexábel. No entanto, pódese tentar un achegamento á cerna dun relato memorístico onde a maioría dos seus elementos parecen encaixar nun esquema solidamente estruturado, ao tempo que tornan en pezas dunha identidade persoal relacionada coa construción da imaxe dun forte liderado e cun concepto de masculinidade non excluínte da presenza de elementos pretendidamente femininos como a tenrura, a sensibilidade ou a compaixón.

En esencia, a memoria da experiencia de guerra de Líster céntrase no pobo, nos homes e mulleres convertidos de súpeto en soldados e abocados ao transo da violencia, aos actos transcendentais de matar ou morrer e, en definitiva, no suxeito colectivo que conforma o Ejército Popular de la República (EPR) como un exército de voluntarios cuxa estrutura e regulamentos estanse a estruturar sobre a marcha, no mesmo campo de batalla (Líster 2007: 133). Trátase da imaxe dun heroe colectivo que camiña cara á derrota e aínda así continúa a pelexar. $\mathrm{O}$ autor e o suxeito popular móvense pola forza intrínseca do deber emancipador, revolucionario, e da obriga humana conectada á misión liberadora das clases traballadoras oprimidas polo sistema onde medra a ameaza fascista, e isto tradúcese nunha narrativa rica en palabras e conceptos referentes á mística do pobo, da guerra nacional revolucionaria ou da lealdade e a disciplina.

Nas constantes referencias aos soldados do bando nacional ou "inimigo" non se busca a carga denigratoria (en determinados momentos, fálase de fascistas de modo xenérico, ou de estranxeiros citando os marroquís e os membros da Legión Extranjera sen enfatizar ningunha emoción), debido seguramente tanto 
ao interese de Líster por manter unha liña de presunta obxectividade fortalecedora dos fins pedagóxicos pretendidos, como á configuración dunha cultura de guerra na que se acentuaría da culpabilidade das elites por parte dos comunistas.

$\mathrm{Na}$ ollada retrospectiva de Líster, a mística do pobo transcende as súas vivencias persoais -presentes no núcleo das memorias-e desvela a forza do movemento voluntario dende o que se constrúe o exército republicano, totalmente incrustado nas clases populares que lle dan o pulo necesario para subsistir. Un protagonista dese calibre, consciente da súa misión esencial, cadra evidentemente nun enfoque coherente coa bagaxe política e humana do militar e político comunista galego, mais, como imos ver axiña, ese suxeito abstracto faise visíbel tanto na escritura como na oralidade dun relato tecido para debuxar traxectorias vitais concretas acordadas. Así pois, fálase de pobo pero non tanto de patria, pois a perspectiva do tempo parece ter difuminado, polo menos na memoria de Líster, o uso do nacionalismo como factor mobilizador no que os comunistas prosoviéticos foron pioneiros dentro do bando republicano malia constituír a priori a forza máis internacionalista do bando gobernamental (Núñez Seixas 2012: 55).

Esta narrativa emerxería, non obstante, dunha análise moi selectiva, pendurando entre pasaxes moi descritivas (relativas fundamentalmente a aspectos organizativos) e elipses bastante significativas, relativas a determinados acontecementos onde o seu papel foi clave, como por exemplo as batallas de Madrid e Teruel ou a disolución do Consejo de Aragón. E a elaboración da mística do pobo implica necesariamente un proceso de transformación do significado da guerra a ollos dun antigo axitador e propagandista comunista adestrado no período de entreguerras, que tras experimentar os combates -tanto os do campo de batalla coma os ideolóxicos, prolongados estes últimos durante décadas- escribe e recorda o feito bélico como unha "guerra progresista" ou "la más grande epopeya de la historia moderna española" (Líster 1966: 272).

Porén, o retrato da violencia como fenómeno antropolóxico xorde dunha forma indirecta, atribuíndoselle especialmente un papel xerador de accións de sacrificio ou combates heroicos, significados ou valores de interese puramente estratéxico ou militar. Outra peza a ter en consideración para captar mellor a complexidade destes relatos dedúcese do feito de que o mesmo acto de narrar o sucedido en combate, o acontecido no seu tempo histórico e despois lembrado, moldea e modifica a propia experiencia de guerra e iso non pode pasar desapercibido (Bourke 2008: 18).

Evidentemente, aparecen retratos de acción bélica, imaxes violentas, moi duras, experimentadas en primeira liña, ás veces frescos case surrealistas, pero non fan por traspasar o plano narrativo e ofrecerlle ao lector o ángulo cego do relato, relacionado cunha estrutura profunda existente para o conflito humano, como así a define S. Kalyvas (2010: 24). Isto é, non se eleva o ton emocional nestas escenas de acción como si se ha facer na rememoración dos camaradas ou subordinados desaparecidos ou na expresión do sentido pola causa popular da República e os seus valorosos defensores. Aínda así, aparecen fragmentos vibrantes como o plasmado na narración do caos vivido nun episodio clave do asedio ao Alcázar toledano:

Hacia la madrugada del día 27 al 28, cuando estaba reconociendo nuestras posiciones alrededor del Alcázar, vinieron a decirme que en el puente de San Martín había lío entre el destacamento que yo había colocado allí y grupos de milicianos y guardias de Asalto que querían marcharse de la ciudad. Salí rápidamente para allá y me encontré con un regular follón, los unos querían cruzar el puente y los otros les amenazaban con dos ametralladoras que yo había hecho colocar a la salida del mismo. El que más chillaba era un capitán de Asalto, que a toda costa quería imponer su autoridad para salir pitando. Me dirigí a él afeándole su conducta. En ese momento oigo un tiro a mi espalda y vuelvo rápidamente la cabeza para ver caer, casi sobre mí, a un sargento de Asalto al que mi ayudante le acababa de pegar un tiro en la cabeza en el mismo momento en que él se disponía a pegarme un tiro por la espalda. Con su brazo en cabestrillo, Chicharro -que había de morir después a las puertas de Madrid- acababa de salvarme la vida a mí y a otros, pues mi muerte, en tales condiciones, hubiese venido a agravar la confusión. Desde ese momento se acabó toda discusión, los que estaban dispuestos a seguir combatiendo volvieron a la ciudad y los otros fueron desarmados y degradados los que tenían algún grado. (Líster 1977: 114)

Esta escena, semellante dende logo ás ofrecidas polo cine negro ou bélico, fálanos tanto da cruzada emprendida polo militar galego contra os desertores como dos problemas políticos e estruturais que afectaron á organización do EPR e ao sistema de forzas que termaba dos 
diferentes gobernos republicanos. Neste caso, obsérvase como os enfrontamentos de Líster con mandos do exército ou da policía profesional case lle custan a vida, situación non moi distinta da que lle aconteceu, entre outros momentos, no seu trato cos anarquistas, que estiveron a piques de despachalo sen máis no propio cine Europa en Madrid.

Dende logo, a asertividade narrativa ás veces cede e pódense achar pasaxes máis vivas, ou mellor, vividas, nas que xorde de súpeto a pura realidade da guerra, a danza de violencia cega e morte provocada polo combate e descrita con fondos trazos de ruda humanidade por quen quizais foi ou albergou crenzas ou principios pacifistas durante algunhas fases da súa vida. En referencia aos combates do 7 de novembro en Villaverde -pouco antes escribía verbo de escenas semellantes nos combates polo Alto del León-, nos inicios da batalla de Madrid, di isto:

El choque fue brutal entre aquellos ejércitos, borrachos de victorias desde Sevilla a Madrid, y los defensores de la libertad que habían decidido morir antes de dar un paso atrás. La $1^{\mathrm{a}}$. brigada no sólo estaba dispuesta a no retroceder, sino que después de parar al enemigo en seco, contraatacó y comenzó entonces una secuencia de combates feroces donde las armas principales eran la bomba de mano y la bayoneta; y así en cada calle, en cada casa, en cada habitación, no sabiendo muchas veces si se mataba a un enemigo o a un compañero. Luego todo se fue estabilizando. Era una lucha de forcejeos, en la que unas veces se ganaban unos metros y otras se perdían. Estos combates no tenían una importancia decisiva desde el punto de vista del terreno, pero reforzaban la combatividad de las tropas y se detenía y debilitaba al enemigo. (Líster 1977: 171)

En paralelo aos posíbeis enfoques e vías narrativas sinaladas antes, subxace unha certa naturalización ou normalización do combate, da combatividade por riba do valor estritamente dos obxectivos materiais ou territoriais a conquerir, como modo de expresar a violencia -linguaxe ritualizada, graduada e compartida polos soldados de ambos bandos en liza- que conecta co modelo un tanto ambiguo ou matizado de masculinidade tradicional representado nas memorias de Líster.

As big words -pódense colleitar dentro do espazo ou a dimensión humanizada fóra dun valor instrumental ou ideolóxico- non se explicitan no texto, aínda que os recordos da súa experiencia de guerra moitas veces pidan unha reflexión que non chega ou fica á marxe do eixo do relato. Non se medita en profundidade sobre o acto de matar nin aparecen a culpa e os remorsos, aínda que diso hase facer algún apunte ao final deste traballo. Excepto, por suposto, da intermitencia das dicotomías $v a$ lentía-covardia - na procura dos heroes tanto individual, en xeral morto ou ferido como resultado do seu sacrificio, como grupal ou abstracto- ou lealdade-traizón, dotadas especialmente dunha funcionalidade político-militar, conectada a unha obriga moral.

A interpretación da noción de camaradería prevalente nas memorias de Líster achégase á versión desenvolvida polos veteranos de guerra esquerdistas que escribiron despois das dúas guerras mundiais, especialmente tras a primeira, baseada nunha visión fraternalista e integradora nunha comunidade global dos traballadores afastados artificialmente por bandeiras, gobernos espurios, credenciais políticas e a realidade da masacre cotiá.

Esa perspectiva está implícita na percepción do militar e político galego acerca da "tragedia interior" dun dirixente anarquista como Buenaventura Durruti, lembrado significativamente como "aquel hombre fuerte y bueno, combatiente de coraje, víctima en ese momento de las ideas que él había sembrado" (Líster 1977: 175), morto en plena batalla de Madrid en medio dunha actuación moi controvertida das forzas ao seu mando. Porén, non se perfila unha identidade proletaria compartida coas masas de traballadores e campesiños obrigados a loitar no bando franquista (aínda que podería deducirse, por exemplo, ao enfatizar o autor a culpabilidade absoluta das oligarquías españolas no estalido da guerra civil), estratexia máis opaca que a seguida polo autor noutros documentos escritos e entrevistas. En todo caso, o recurso intermitente do humor basta para empatizar, en certa maneira, con eses soldados galegos do bando nacional que foron obrigados a vestir xilabas para pasar por mouros e así aterrorizar a unha unidade republicana, dada a aura de crueldade que acompañaba aos soldados norteafricanos do exército nacional.

Moito máis sólido semella, loxicamente, como imos ver, o debuxo do vínculo trazado cos propios soldados civís do exército popular -tamén viciado interiormente pola xerarquía clasista de moitos mandos profesionais e mais dalgúns dos seus imitadores saídos dos cadros milicianos-, membros do pobo, traballadores, obreiros e labregos, circunstancia que permite unha lectura en perspectiva moi reveladora. 
Un novo tempo histórico revelaba un novo tipo de relacións sociais e, por esa razón, demandaba unha transformación profunda na estrutura dun exército popular que permitise axustar a xerarquía á orde xurdida do combate ou da experiencia de guerra no seu conxunto. Segundo a visión de Líster, tíñase que acadar un modelo onde non importase se os oficiais e mandos procedían das milicias ou do antigo exército profesional -tamén louvados polo autor cando os vía cumprir co seu deber-e, así mesmo, se priorizase os mellores ou máis capacitados: unha selección por mérito que boa parte da cúpula do EPR non soubo entender, aferrada aos canons decimonónicos ou a criterios partidistas. Dende estes parámetros, rexéitase a teoría que explicaba o fracaso do EPR en función da carencia de mandos intermedios e ponse a diana en membros da súa cúpula $(\mathrm{Ca}-$ sado, Miaja...) ou homes de prol como Prieto.

Malia que Líster non banaliza a realidade nin fala dunha guerra idealizada na fasquía da violencia, estes textos non deixan de ser políticos, nin de estar suxeitos a diversos nesgos ideolóxicos ou antropolóxicos que, obviamente, revelan unha forte carga de subxectividade. O concepto de masculinidade que impregna as memorias de Líster móvese entre os vigorosos estereotipos normativos burgueses para tempos de paz ou períodos bélicos, segundo o caso, e a virilidade agresiva adaptada á linguaxe comunista de inspiración soviética, creador da imaxe dun novo home aberto á mística da solidariedade ou á fraternidade universal e convertido en guerreiro de modo azaroso.

Esa mestura implicaría, no filtrado ideolóxico realizado por Líster, acentuar o valor do sacrificio pola causa do proletariado (os camaradas dentro e fóra das trincheiras), do deber e a dignidade, da disciplina e a forza de vontade, do heroe colectivo (o pobo como suxeito integrador das masculinidades individuais) e non tanto da guerra como aventura, perspectiva que non encaixaba nas súas premisas políticas e humanistas.

A idea de masculinidade manexada por comunistas españois asimilou con naturalidade, na súa narrativa, a contradición semántica afrontada ao esgrimir selectivamente o seu antimilitarismo (a oposición ao exército en tanto instrumento da oligarquía) e asemade defender o discurso teórico da loita de clases e a guerra nacional revolucionaria, termo postulado de modo continuado nos seus textos, para non deturpar a visión ofrecida. Por iso se desdebuxaron as pegadas das teses pacifistas e universalistas e se ralentizaron os modelos de masculinidade renovados cara ao futuro. No fundamental, Líster subliñaba o perfil dunha comunidade de homes rectos, honestos, esforzados en manter a súa dignidade e o compromiso cunha causa destinada á derrota, marcando unha clara distancia con boa parte da clase política ou militar republicana.

Os trazos da masculinidade comunista desenvoltos no período de entreguerras igualaban ata certo punto homes e mulleres. Emporiso, ficarían sombras de difícil erradicación, como imos ver. No caso de Líster, o recordo sentido e laudatorio de Antonia Portero non deixa de estar subordinado ao dos seus compañeiros varóns: militante da JSU morta na batalla de Guadalajara aos dezasete anos, fálase dela como dunha "verdadera heroína forjada en los combates de Guadarrama y Madrid", cuxa afouteza "había conquistado la confianza de los hombres más curtidos en la lucha" (1966: 112). Esta afirmación confire a unha muller un rango simbólico acaparado polos homes (neste caso, os veteranos deben validar os méritos da miliciana), pero non chega a rachar un criterio compartido, aínda que con matices, polo militar galego e a maioría dos comunistas ortodoxos, que continuaba a reservar para a muller o papel esencial de nais e rexeitaba, por certo, o amor libre e a prostitución, seguindo os cánons leninistas. En concreto, recrimínase aos anarquistas que asediaron o Alcázar durante dous meses que foran acompañados de "varios centenares de 'señoras', también con pañuelo rojo y negro, llevadas de los burdeles de Madrid", coas que "se dieron la gran vida luchando contra unas piedras detrás de las cuales se 'defendían' unos señores que, si no lo pasaban tan bien como los "atacantes" anarquistas, lo pasaban bastante mejor que sus compañeros batiéndose en el frente" (Líster 1977: 115).

Pódense achar episodios aínda máis claros de asimilación ou proceso progresivo da masculinidade normativa a través dos textos analizados, menos compatíbeis coa visión das mulleres como suxeitos pacíficos, débiles, que co seu rol sexual tradicional e, talvez por iso, narrados cun ton bastante coloquial. Por exemplo, unha declaración de intencións no prólogo á edición de 1977 das súas memorias, síntese do tratado con anterioridade e boa mostra de determinadas emocións sociais, non excluídas tampouco da noción de camaradería manexada: "he procurado no caer en mi relato ni en la fanfarronería ni en el lloriqueo, dos cosas que están hoy muy de moda, pero que a mi 
siempre me han repugnado y a los setenta años me dan verdadero asco" (Líster 1977: 8). Ou, na mesma dirección apuntada, unha alusión ás queridas de xenerais e mandos republicanos aos que atopou ben acompañados de "buenas mozas" en varios episodios que remataron en astracanadas.

No plano estrito da escritura e o recordo, George Mosse advirte que a verdadeira masculinidade pode xerar na memoria unha nova dimensión de brutalidade asociada á noción de liberdade individual proporcionada polo combate e, por extensión, ao argumento precedente do cumprimento do deber (2001: 130). Porén, as connotacións de brutalidade, agresividade ou crueldade contidas na rememoración da experiencia de guerra pódense compensar, $a$ priori, cunha firme apelación á idea global de camaradería. Esta convértese nun recurso tanto para que os veteranos da Wehrmacht xustificaran durante décadas, cara á sociedade alemá, a fidelidade ao proxecto xenocida de Hitler, como para que un miliciano como Líster, en coordenadas ideolóxicas e históricas cambiantes, louvase a estreita relación estabelecida cos seus soldados e subordinados proletarios (compañeiros de infortunios heroicos) no EPR. Unha versión humanizada dun modelo disciplinario, non obstante moi rigoroso, destinado a proporcionar coidados e atencións á tropa (servizos sanitarios eficientes, comida e auga fresca en tempo, apoio cultural-Batallón do Talento - e ata a orquestra amenizadora dos combates), e a reforzar a moral dos soldados, asegurándolles que nunca serían abandonados, para optimizar tamén o seu rendemento no combate. Por tanto, Líster lembra que puña sempre o seu posto de mando en primeira liña para compartir a sorte dos seus camaradas ou subordinados -como se fose un membro do Batallón especial, a unidade coa que sempre cubría as fendas da fronte ou tentaba resolver as situacións críticas- e, ao tempo, observar de cerca os movementos do inimigo, táctica adoptada para poder esixir despois aos seus un valor e compromiso semellante.

Precisamente por iso esta postura de empatía medida implicaría, obviamente, unha reciprocidade concreta equivalente a unha interpretación ríxida da disciplina, traducida en códigos estritos a aplicar nos casos de traizón ou deslealdade, capaces de xustificar tamén o relato da execución dun quintacolumnista, médico do exército republicano, no que se subliña a valentía amosada polo reo antes de ser fusilado. Estes códigos reflíctense nas memorias de
Líster entre certa indiferenza mal disimulada e un punto inevitábel de crueldade, derivada máis da ausencia de pulo emocional no relato que da narración de escenas escabrosas ou sádicas, fixado o texto na noticia esporádica de feitos onde se aplicou a pena capital sen diplomacia ningunha, dada a pretendida solidez moral e xurídica das razóns esgrimidas para adoptar tal medida.

Despois da II guerra mundial callou en Europa, e fundamentalmente en Alemaña, unha lectura presentista da comradeship ou camaradería que, entre outras funcións -incluída a integrativa nos procesos de construción das sociedades democráticas da guerra fría-, axudaría a facer a guerra e o seu recordo máis soportábel para os que a viviron (Thomas Khüne 2017: 279). Esta visión esgotaríase no caso xermano para a década dos oitenta do século $\mathrm{XX}$, ao se impoñer unha visión contraria á interpretación da camaradería como unha maneira de humanizar a guerra. Khüne describe a memoria dos veteranos de guerra e o seu enfoque da idea de camaradería como "epítome of the "human", i.e altruistic, and affectionate side of the comunity of the suffering", ofrecendo argumentos que permiten atinxir a especial conexión estabelecida entre as experiencias contidas nunha definición comprensiva de comradeship e un concepto de masculinidade flexibel ou plural dentro do mundo militar, nunca illado, monolítico ou hexemónico. Comradeship entón significaría unha forma de reconciliar ou harmonizar diferentes personalidades, identidades, xerarquías, emocións e posicións ideolóxicas ou relixiosas, e implicaría paralelamente un tipo de masculinidade endurecida que, malia estar constituída polos elementos de agresividade e control que a vida militar require, integraría un modelo de femininely code affection (Thomas Khüne 2017: 240-241 e 291-293). Este tipo de afecto posuiría, teoricamente, as claves da tolerancia fronte a fracturas emocionais ou intres de debilidade, tenrura, empatía e compaixón, valores dunha nova identidade compartida como soldados ou loitadores para transcender a condición civil de orixe. Unha relación de pertenza efectiva, así pois, a unha comunidade global vertebrada sobre o compromiso de clase nos campos de batalla e, xa dentro da dimensión do recordo, nos propios relatos dos excombatentes, sexan estes militares profesionais, conscritos ou voluntarios.

A camaradería no EPR - orientada, na memoria de Líster, cara a fórmulas de afecto, 
fraternidade e solidariedade de clase--, vaise relacionar cun concepto de disciplina moi ideoloxizado, formalmente máis laxo e aberto. Trátase dunha categoría non tan asociada á clasificación do soldado, do miliciano, como unha simple peza do taboleiro de xadrez do campo de batalla, no que o relato exclúe selectivamente profundar no castigo os delitos de desobediencia ou traizón, severidade habitual en situacións de guerra e difícil de recoñecer no discurso comunista de raíces antimilitaristas, por ambiguas que estas sexan.

Como David Morgan suxire, " it is the interplay between military cultures and factors in the wider societiy as a whole that shape masculinities, rather than simply the military cultures in isolation" (1994: 176), premisa que axuda a analizar as distintas olladas proxectadas por un miliciano como Líster (elevado á cúpula militar do EPR e, con posterioridade, dos exércitos soviético e iugoslavo) sobre a guerra civil, a natureza do combate, o exilio e a ditadura franquista. Isto non só revela a complexidade da memoria legada polo militante comunista galego e o seu alongado tempo histórico, senón que amosa o perfil do heroe colectivo, grupal, armado dun valor que non posúe realmente, senón que chega a enraizar nos procesos de socialización e ideoloxización de xeito comparábel, pois é a propia experiencia de guerra a que se vai encargar de absorber as disonancias de modo progresivo. Un heroe, o mito proxectado polos códigos de masculinidade tradicionais, que adquire a súa condición por demostrar sobre todo tenacidade no combate e resistencia máxima fronte á fatalidade: os erros de prospectiva dos políticos, as carencias materiais e as traizóns internas e externas (o abandono da República por parte das democracias occidentais) que impediron a vitoria republicana.

Esa resiliencia colectiva dos soldados republicanos, vista practicamente como a máis poderosa das armas de combate para acadar o triunfo moral -asumida a dificultade de derrotar os ben abastecidos fascistas-, vaise expresar cun ton firme pola confianza nas propias forzas, a pesar da derrota final presentida e lembrada máis tarde ata o punto que Líster parece agardar aínda algo delas máis de trinta anos despois de acabada a guerra. Unha autoconfianza individual e colectiva impregnada de arrogancia ou de soberbia no intre de afirmar de modo taxativo que Franco non tería tomado Madrid no caso de non se deter o avance dos nacionais en Toledo para liberar o Alcázar ou de fe ideolóxica nunhas teses políticas de construción dun suxeito mítico cunha linguaxe ben estereotipada, o pobo, a masa heroica comprometida coa guerra nacional revolucionaria, outro concepto francamente revelador:

El heroísmo de masas en la guerra era el resultado lógico de las nuevas condiciones surgidas después de la sublevación. La abnegación y el espíritu combativo del nuevo Ejército, como los del pueblo español, su creador, eran el reflejo ideológico de un nuevo régimen; de las nuevas relaciones económicas y sociales que nacían al aplastar a la reacción fascista. Eran la expresión del inquebrantable enlace entre el heroísmo guerrero y popular y el carácter político de la guerra. (Líster 1966: 292)

Os rostros dese pobo heroico pódense identificar dende un punto de vista humano a partir da detección das emocións, estratexia na que o militar e político galego se vale da épica contida nalgúns poemas de formas de lectura:

Mientras el poeta iba leyendo su poesía, yo me fijaba en los rostros de los combatientes e iba leyendo en ellos el efecto de lo que escuchaban, y podría decir, sin temor a equivocarme, que en muchas caras veía que éste o aquél iba a ser un héroe en el próximo combate.

Líster recoñécese partidario dos discursos curtos, directos e dirixidos ao corazón, e dá ese argumento para enfatizar o seu amor pola poesía, presente nos órganos de prensa do Quinto Regimiento e espallada na pluma e na acción de poetas-soldados do Batallón del Talento, como Miguel Hernández ou José Herrera Petere. Dende a súa óptica, a lectura ou a práctica da poesía na publicación que se quixese $(M i-$ licia Popular, El Mono Azul...) ou en recitais organizados na fronte atesouraba tamén un valor taumatúrxico, un efecto capaz tanto de reforzar a moral como de transformar a persoa, independentemente da súa condición de orixe, nun combatente real. Estábase a procurar un soldado disposto a morrer pola causa, que dese xeito adquire directamente os galóns reflectidos pola súa ousadía e esforzo reais no campo de batalla.

A aura guerreira, case épica, dun Líster investido do mesmo liderado e rol simbólico xogado por Vasili Chapáyev na guerra civil rusa -o soldado de tropa elevado a rango e xerarquía de mando debido aos seus méritos de combate- redundou no crecente prestixio adquirido polo Quinto Regimiento, unha unidade á que -lembra con indisimulado orgullo 
o miliciano galego- moitos soldados republicanos querían ser destinados. Chapáyev tivo, emporiso, un final tráxico xa que afogou no río Ural en 1919, dando así comezo a un culto á súa figura traducido na difusión de novelas e filmes de gran éxito no seu momento tanto na URSS coma na España da Segunda República e o exilio.

\section{Repertorios emocionais ou a memoria fron- te ao espello}

A personalidade histórica de Enrique Líster, a súa pose pública -difícil de distinguir da privada, do seu habitar nos espazos íntimos--, estaba tinguida de actitudes arrogantes e provocadoras ata na escrita, propias dun tipo duro, dun líder curtido no trato coa xente común, os seus iguais (polos que sentía unha tenrura real), dun home de acción sobre o que recaían misións e obxectivos militares de arriscada execución, moitas veces de noite, a gran aliada dun exército pobre (Ledo 2007: $\mathrm{min}$. 39).

Pero nela tamén contaba a súa proverbial sinceridade, o seu selo paternal de rectitude e dignidade -a imaxe que lle sería atribuída e non rexeitaría substancialmente-, que tamén reflectía valores, cualidades, emocións e sentimentos de fondo orgullo.

$\mathrm{Na}$ escrita, a dignidade, un dos principais sentimentos que aparecen no texto -neste caso, válennos como emocións prolongadas no tempo-, entronca co orgullo por mor da actitude xenerosa, valente, sacrificada de tantos loitadores por unha causa tornada en utopía debido a unha cadea de imprevisións e neglixencias. Erros en conxunto dos que o autor non pretende desmarcarse en absoluto -por máis que reivindique a súa actuación e a dos seus e critique duramente os traidores e pasivos-, malia sinalar a importancia de dispor da suficiente perspectiva para xulgar os feitos con máis precisión.

Seica tamén que a opción do sacrificio procede en boa medida do concepto de valor en tanto "realidade" tanxíbel -por máis contradicións que chegue a proxectar-, tal como é definido por Lord Moran no senso da "superación consciente del miedo a través de la autodisciplina" (2018: 151). No espléndido documental dirixido por Margarita Ledo, Liste, pronunciado Lister, o militar e político galego refire o debate mantido no seo do Batallón del Talento, unha unidade formada por poetas, escritores e artistas de toda clase que pertencía ao Quinto Regimiento e se encargaba de facer o traballo cultural entre os soldados. Na súa rememoración, Líster esvaece de modo consciente a fronteira entre a virtude do valor, da valentía, e o medo como emocións ou conceptos culturais intimamente asociados aos rituais e valores relativos a cumprir o deber e a dignidade persoal e colectiva, obrigas que deben prevalecer -confesa o propio interpelado nun intre especialmente intenso- "aunque se le estén encogiendo a uno los cojones" (Margarita Ledo 2007: $\min .50 .48$ a 52.30). Esta confesión explícita verbo dunha emoción primaria tan relevante para a experiencia de guerra non implica, emporiso, unha reflexión profunda acerca de asuntos humanos primordiais como a morte, o medo ou o acto mesmo de matar e as súas consecuencias. Iso non ten cabida na enerxía do relato, inmunizada fronte a pescudas alambicadas ou mesmo cuestións excesivamente densas.

Líster argúe a misión transcendental autoasignada -o cumprimento do deber outra vez como fonte de dignidade- para explicar a súa obsesión en ficar de pé, ou exposto ao perigo en todo caso, despois de ter enviado os seus subordinados aos refuxios ou velos guindarse polo chan para se protexer das balas. Balas que a Líster lle amolan certamente e ante as que debe amosar indiferenza debido ás esixencias de autodisciplina impostas polo seu liderado e carisma. No seu esquema de valores, a expresión literal utilizada por Líster (me jode) para cadrar o sentimento producido polas balas revelaría, pois, un tipo de pudor masculinizado a recoñecer o propio medo. Así pois, resolve as dúbidas e contradicións xeradas polo que sente no acto de memoria ao agochar habilmente unha emoción primaria non só provocada pola propia experiencia de guerra (a proximidade do sufrimento e a morte), senón polo íntimo rexeitamento da pasividade, o derrotismo ou da indiferenza ante a inxustiza, posturas das que se nutría o inimigo de clase.

Ese pudor obriga tamén ao autor a mostrarse extraordinariamente mordaz cos actos considerados de covardía ou falta do debido compromiso, nunhas pasaxes que van da acritude ao humor negro. Aparece, entón, tan mordaz como aséptico (ou arrogante ás veces, segundo cadra) á hora de narrar o balazo que recibe nunha man nos combates do Alto del León en agosto do 36. A retranca parece tamén útil para describir actos de ousadía extrema realizados por soldados republicanos: pensemos na imaxe 
do anónimo segador galego que, poñéndose por diante dos tanques republicanos, baleira el só unha trincheira franquista, colocando amodo unha metralladora a tan só uns metros do inimigo, e recolle o capote do comandante rebelde acribillado como agasallo para un Líster que non deu saído do seu abraio en tantos anos.

Desta maneira, ao posuír símbolos ambiguos, mestizos, enraizados en emocións moi poderosas na perspectiva do tempo, a voz narrativa de Líster resoa nun dobre rexistro, pois reserva unha idea abstracta para o plano discursivo da mobilización - de ser esta aínda posíbel-e, por outra banda, proxecta unha ollada ao pasado que recolle a pegada física e mental dunha experiencia profundamente humana.

Emocións como o medo, a vergonza, a culpa ou o odio subxacen no relato memorístico da experiencia individual e colectiva. Mesturadas necesariamente, nunca ben definidas, subordínanse obviamente á mística do cumprimento do deber e o sacrificio por unha causa que transcendería calquera xuízo de natureza ética ou moral. Pódese afirmar que as emocións sociais citadas fican agochadas, desprazadas ou á marxe do texto, inseridas en procesos psicolóxicos de negación dun trauma posíbel ou de autoafirmación, quizais eclipsadas por unha narrativa política destinada a proxectar toda a responsabilidade do conflito -e con ela a eiva da culpa e da vergonza- e as súas secuelas ao inimigo de clase, a oligarquía, e o seu instrumento máis poderoso, o exército fascistizado. Nese sentido, Líster culpa tamén a Guardia Civil como institución ao servizo de caciques e poderosos no control da vida local, chegando ao punto de recoñecer explicitamente o odio ritual que esta lle inspiraba, un "sentimento mutuo", subliñado precisamente para reforzar un arquetipo cultural construído durante décadas de loita campesiña (Líster 1977: 25).

No acto de se mergullar no pasado, revélase no suxeito unha dimensión emocional nidia que respondería case mecanicamente ao recordo e á memoria, "y la memoria suele estar ligada a los rituales religiosos y a los hábitos de pensamiento que los rituales forman" (Martha Nussbaum 2014: 164). Se partimos da premisa de que os hábitos de pensamento ou a ideoloxía dun home que quere ser recordado como un eterno revolucionario, un loitador irredimíbel pola causa do pobo, poden constituír unha forma persoal de profesar unha relixión civil, parecería oportuno entón introducir neste esquema a emoción social probabelmente máis fonda que latexa nas memorias de Líster, a compaixón.

En certo modo, o dirixente comunista galego considérase -así tamén é recoñecido por moitos dos seus subordinados- como o pai adoptivo dos soldados pertencentes ás unidades por el comandadas, nos intres de vivir e logo lembrar a experiencia de guerra que ha marcar as súas vidas cun selo visíbel ao longo do tempo. Deles coida nos aspectos material e moral, como xefe militar esixente que é -como xa se ten dito aquí-, pero na súa narrativa selectiva, e allea ás dúbidas polo xeral, agroma con frecuencia un humor adaptativo que forma parte da súa identidade. Un recurso perfecto para revelar un sentimento máis complexo e facer xustiza co recordo ao suxerir cunha retranca ben traballada tanto a cronicidade das "espantadas" na fase de formación do EPR, como o papel heroico dos improvisados soldados republicanos ao redimirse en acto de combate:

Alguien ha llamado a ese periodo de Talavera el de las "carreras heroicas", nombre que creo le va bien, pues aquellos hombres que ante la noticia-verdadera o falsa-de que la caballería mora estaba rebasando nuestros flancos había surgido a nuestra retaguardia, salían corriendo, volvían un par de horas después al ataque, derrochando verdadero heroísmo para reconquistar las posiciones que poco antes habían abandonado ante el temor del cerco. (Líster 1977: 109)

Unha relación paterno-filial que se torna compasiva no senso de rescatar nomes de homes e mulleres que deron a vida ou foron feridos gravemente no transcurso de cada combate, de cada batalla significativa da que Líster escribe enfatizando o valor intrínseco do sacrificio pola causa republicana. Sempre se lembra deles e parece que de ter espazo dabondo engadiría moitas máis historias, referencias, recordos de vidas truncadas ou esmagadas, de xente común forzada a loitar e desaparecer tras a loita en tumbas con ou sen nome, celas en algures ou nos distintos exilios.

Emporiso a súa compaixón non contén os matices de superioridade ou piedade que normalmente se atribúen a esta emoción. O sentimento de compaixón acompáñao a través do tempo e ao lembrar e escribir estabelece unha relación de igualdade ou asimilación entre o suxeito que recorda e os seus compañeiros nunca esquecidos, que foron na maioría dos casos os seus subordinados pero que no campo 
de batalla da memoria figuran unicamente como camaradas, xeralmente de infortunio.

Juan Carlos Melich afirma que a compaixón "no tiene nada que ver con el hecho de ponerse en el lugar del otro, algo, por otra parte, tremendamente altivo y orgulloso". Para este autor a compaixón significa "acompañar y acoger, situarse al lado del que sufre" -isto é, nun mesmo plano-, mentres que a piedade se podería ver como "compasión pervertida" (2010: 88). Neste mesmo senso cultural, a emoción ou o sentimento compasivo tamén pode entenderse como unha forma de empatía que implica accións en favor de alguén, neste caso actos de memoria e escritura. As emocións non serían neste contexto accións per se, senón que constituirían a enerxía que lle dá carácter a unha acción, e o que lles confire esa capacidade de proxectar esa enerxía e a súa natureza composta de significados culturais e relacións sociais fusionadas (Ilioz 2007: 15).

Nun plano teórico artellado baixo a ollada vulnerábel da memoria, revélase a vía onde os recordos espertan emocións e estas alimentan lembranzas nun proceso de ritmo incerto, pois todos os elementos e pezas involucradas mestúranse de forma natural, contaminándose as unhas ás outras. Como afirma Sara Ahmed, "el recuerdo puede ser el objeto de un sentimiento en ambos sentidos: el sentimiento adquiere forma por el contacto con el recuerdo, y también significa una orientación hacia lo que se recuerda" (2015: 28). Deste xeito, pódese sentir dolor cando se recorda unha determinada escena, e ao recordar tal evento pódeselle atribuír a casualidade de doloroso ao que se lembra. Este mapa conceptual complícase un tanto se partimos da premisa de que as emocións non son respostas corporais ou cerebrais puras, nin moito menos construcións culturais totalmente independentes entre si.

Por tanto, ao necesitarse a simbiose entre o obxecto e a emoción, unha das características sobranceiras do relato memorístico da experiencia de guerra de Líster atópase na decisión de complementar, ou mesmo rematar, cada epígrafe dedicado a unha batalla ou acontecemento bélico relevante con referencias biográficas aos soldados ou oficiais mortos ou feridos (membros xeralmente das unidades comandadas por el) no transcurso delas. Esta tendencia revela tanto a solidez no tempo dos vínculos da camaradería e o compañeirismo, como a dificultade de definir fronteiras entre emocións sociais como o orgullo e a compaixón. Líster sempre sentiu orgullo da procedencia -traballadores, obreiros, estudantes- da maioría dos mandos das unidades que dirixiu e de boa parte dos responsábeis das divisións e brigadas do EPR, algo que sen dúbida se relacionaba coa identidade civil compartida e, en determinados casos, co sangue derramado.

Véxase, como exemplo, o que Enrique Líster escribe a partir das súas memorias das secuelas da batalla do Jarama en febreiro de 1937:

Entre nuestros muertos, muchos mandos y comisarios. De la 11 División, los jefes de Batallón, Salvador Cruz, obrero metalúrgico de Lisboa, comunista perseguido en su país y que desde el primer día de la sublevación se había distinguido por su heroísmo y capacidad; Gumersindo Carmona, jefe del batallón Gallego (...) Antonio García Melchor, miembro del comité de un Partido de un Batallón, muerto cuando acababa de arrebatar un fusil ametrallador al enemigo. Los comisarios Domingo Pazos, Manuel Pérez, Francisco Sánchez, José Román (...) En el Jarama murió Eduardo Belmonte. Era comisario de la 8 División y llegó en servicio de inspección al sector del Jarama, en los momentos en que se luchaba con más encarnizamiento y al caer herido un comisario de Brigada, él ocupó su puesto. Cuando, moribundo ya, era evacuado pronunció estas palabras: "he sido el primero en avanzar y el último en retroceder. He cumplido con mi deber de comisario". Palabras que habían de convertirse en la divisa de los comisarios. (Líster 1966: 102)

Ou o tamén acordado con moita sensibilidade verbo das perdas humanas en Brunete (xullo do mesmo ano), "aquel infierno de metralla y calor terrible" para os combatentes da 11 División:

Gonzalo Pando, jefe de la 9 brigada. Pando era un jefe y un camarada entrañable. Sus soldados le querían, le veneraban. Marchaban con él al combate decididos, animosos, porque se sentían mandados por un hombre que gozaba de toda su confianza y cariño. Había nacido en Villaviciosa (Asturias). La sublevación del 18 de julio le sorprendió en Rascafría, donde ejercía su profesión de médico. Días antes de producirse el levantamiento, movilizó a todos los hombres de izquierda del valle de Rascafría y organizó la defensa del mismo (...) Pando participó en la organización del Batallón "Thaelmann" -él organizó con 200 hombres la $4^{\mathrm{a}}$ compañía, batallón que, en setiembre, él mismo pasaba a mandar (...) Alberto Sánchez, jefe de la $1^{\mathrm{a}}$ Brigada, un ejemplo más de la solidaridad y simpatía con que la juventud del mundo entero miraba a la verdadera España nos lo ofrecía 
este héroe caído en los combates de Brunete en plena juventud, cuando apenas contaba 21 años. Cubano, combatió a la dictadura de Machado, motivo por el cual tuvo que abandonar sus estudios y su tierra trasladándose a España. (Líster 1966: 140-141)

Destes parágrafos, e doutros da mesma natureza vencellados a cada unha das descricións do acontecido nas diferentes batallas nas que Líster participou, pódense deducir bastantes dos elementos constitutivos da narrativa da experiencia de guerra construída polo militar e político galego (camaradería, afecto, amizade, louvanza do heroísmo, homenaxe simbólico ao sacrificio, liñas de continuidade biográfica). Dende unha ollada paternalista, en aparencia ben asumida -o que non lle quita unha fundamentación sincera-, reflíctese un grao de empatía que alumea un acto de memoria e de escritura ou, noutras palabras, unha emoción compasiva mesturada con doses de dolor e orgullo para xerar un contido simbólico. En todo caso, a construción cultural da imaxe dun militante comunista implicaba un traballo de asimilación dun arquetipo onde figuraba tamén a compaixón polo xénero humano como un poderoso signo de identidade persoal e colectiva.

Porén, non todo sentimento de compaixón se proxecta especificamente no recordo dos mortos ou feridos gravemente na loita por unha causa. De feito, ás veces vaise centrar en actos de desobediencia ou simplemente iniciativas arriscadas dirixidas a evitar unha masacre ou a perda inútil de moitos soldados republicanos, como o foi a decisión tomada polo entón xefe da $11^{a}$ División de suspender a ofensiva emprendida no Cerro de los Ángeles para protexer as vidas dos seus soldados, abocados á súa aniquilación debido á superioridade manifesta das defensas franquistas e á descoordinación das unidades comprometidas nas misións. Ante as recriminacións do seu xefe inmediato argüíndo que non se podía facer iso, a arrogancia de Líster -enfocada aquí, como noutros casos, na defensa dos seus soldados, pero tamén en manter un criterio de partida oposto a unha operación condenada ao fracaso- contestou asegurando que "la prueba de que se podía hacer es que yo lo había hecho" (1966: 122). Resulta evidente que o relato memorístico do militar galego procura remarcar a alianza cos débiles ou menos poderosos mentres acentúa o rexeitamento ou mesmo o desprezo mostrado cara a actitudes de individuos caracterizados por Líster como fachendosos ou directamente finxidores, caso de Hemingway (aínda que polo escritor norteamericano parece sentir certa simpatía), Ramón. J. Sénder ou o "Campesino". Os dous últimos reciben nos textos críticas e acusacións moi serias, especialmente Valentín González, un personaxe moi controvertido cuxa actuación durante a guerra ("fuxido" de Teruel tras abandonar os feridos e unha boa parte da súa unidade, destituído no Ebro nada máis comezada a ofensiva por mor dunha "enfermidade") propiciaría o uso do sarcasmo para definila con propiedade.

A compaixón pode xermolar con aínda máis forza, loxicamente, nalgunhas lembranzas do trato brindado aos inimigos ou a membros de colectivos que sufriron a represión republicana, caso das monxas ás que Líster e Dolores Ibárruri prestan protección e transforman en costureiras para a confección de roupa para os soldados do Quinto Regimiento (1966: 72). En hipótese, os prexuízos ideolóxicos ou relixiosos que deberon vencer, canto menos en público, acentuarían así mesmo unha emoción que contamina a escritura na perspectiva do tempo e chega a marcar, xa nun plano máis amplo, a memoria da experiencia de guerra que se vai remodelar en cada contexto da escritura.

\section{Conclusións}

$\mathrm{O}$ relato da experiencia de guerra de Enrique Líster debuxa un escenario ateigado de elementos complexos, definidos polas interpretacións fornecidas sobre os lazos de camaradería entre "iguais" (mandos, oficiais e tropa), que compartirían emblemas milicianos de sacrificio, deber e dignidade (a verdadeira e futura vitoria fronte á certeza da derrota), os alicerces da masculinidade tradicional burguesa, baixo determinadas modificacións, e un corpus emocional rico, consciente e ben conectado ao discurso postulado do texto.

Esa relación de camaradería e, fundamentalmente, de igualdade amplificada na memoria constituiría a base ideolóxica primaria dunha visión proletaria e internacionalista que fica arredor da ortodoxia soviética durante décadas e condiciona a escritura dos recordos dunha guerra que se pensaba aínda gañar no territorio das metáforas, na batalla das palabras.

Non constitúe acaso a doutrina comunista unha expresión teórica apriorística de compaixón polos demais seres humanos? Canto menos, iso parece pensar Líster cando lembra e escribe como homenaxe ás vidas entregadas pola causa, o sangue derramado, fronte ás estruturas oligárquicas, os exércitos fascistas e a 
indiferenza das denominadas potencias democráticas. Aínda que esa perspectiva dependa do cumprimento dunhas regras estritas de pertenza a unha comunidade simbólica e política, sempre pode acharse unha fenda pola que estender emocións máis positivas cara a espazos sociais ou culturais alleos, reservando o odio ou o noxo para obxectos concretos que Líster apenas nomea.

Este esquema contempla a guerra como un desafío crucial dentro do proceso de emancipación dos pobos, normalizándoa fundamentalmente no seu proceso visual a través da narración, sen profundar demasiado no campo emocional proxectado polo fenómeno bélico (quizais debido á propia natureza do combate), á marxe do orgullo que lle produce o sacrificio, a disciplina e a dignidade dilapidadas polos seus soldados.

Talvez por iso se mostra máis firme na definición da guerra civil como un dos dramas do que culpar á oligarquía e ao poder estrutural en abstracto e nas súas formas nacionais e institucionais, algo ao que axuda a interpretación da contenda coma unha loita progresista ou nacional-revolucionaria, literalmente, un reto nacido dunha ameaza. Dende este punto de vista, resulta lóxico desconfiar, cara ao futuro do país, dun modelo de reconciliación ditado exclusivamente polas elites e aceptado submisamente por políticos como Carrillo.

Líster convértese no recordo, como o fixo tamén na realidade - diso non cabe dúbida-, no pai adoptivo dos seus soldados, os realmente comprometidos ou habituados a unha resignación activa, da maioría de loitadores azarosos por unha causa incerta pero sempre presente no seu esforzo. Un pai adoptivo que non concibe a derrota máis alá desa primeira fase constituída pola guerra civil, valla a expresión, pois o seu territorio, sen rexeitar as identidades galega e española, resulta ser o mundo e este atópase nunha loita continua que non pode rexeitar como tampouco rexeita de plano o entronque consciente do mito no relato histórico. As maneiras de loitar poden ser varias, aínda que finalmente escolle a memoria, a escritura e un relato sentido legado ás xeracións máis novas.

\section{Referencias bibliográficas}

Ahmed, Sara (2015): La política cultural de las emociones. México: UNAM.

Bourke, Joanna (2008): Sed de sangre: Historia intima del combate cuerpo a cuerpo en las guerras del siglo XX. Barcelona: Crítica.

Damasio, Antonio (2006): En busca de Spinoza. Barcelona: Crítica.

Erice, Francisco (2009): "El orgullo de 'ser comunista', imagen, autopercepción, memoria e identidad colectiva de los comunistas españoles”, en M. Bueno (ed.), Nosotros los comunistas: memoria, identidad e historia social. Madrid: Fundación de Investigaciones Marxistas.

Hynes, Samuel (1998): Bearing witness to a modern war. New York: Penguin books (Ebook)

Ilioz, Eva (2007): Identidades congeladas. Las emociones en el capitalismo. Buenos Aires: Katz Editores.

Kalyvas, Satathis. N. (2010): La lógica de la violencia en la guerra civil. Madrid: Akal.

Khüne, Thomas (2017): The Rise and Fall of Comradeship: Hitler's Soliders, Male Bonding and Mass Violence in the Twentieth Century. Cambridge: Cambridge University Press.

Lavanyi, Jo (2016): Engaging the emotions in Spanish culture and history. Nashville: Vanderbilt University Press (Ebook).

Ledo, Margarita (2007): Liste, pronunciado Lister. Documental (producido por Xose Luís Ledo Andión).

Ledoux, Joseph (1999): El cerebro emocional. Barcelona: Planeta.

Líster Forján, Enrique (1966): Nuestra Guerra. Aportaciones para una Historia de la Guerra Nacional Revolucionaria del Pueblo Español 1936-1939. París: Editions de la Librairie du Globe (Colección Ebro).

(1977): Memorias de un luchador. 1. Los primeros combates. Madrid: G. del Toro editor.

(2007) Nuestra guerra. Memorias de un luchador. Madrid: Ediciones Silente.

McMoran Wilson, Charles "Lord Moran" (2018): Anatomía del valor. Madrid: Arzalia.

Melich, Juan Carlos (2010): Ética de la compasión. Barcelona: Herder.

Morgado, Ignacio (2007): Emociones e inteligencia social. Barcelona: Ariel.

Morgan, David H. J. (1994): "Theater of war, combat, the military, and masculinities", en H. Brod e M. Kaufman (edit.): Theorizing masculinities. Tousand Oaks, CA: Sage, pp. 165-183.

Moscoso, Javier (2011): Historia cultural del dolor. Madrid: Taurus.

Mosse, George. L. (2001): La imagen del hombre: La creación de la moderna masculinidad. Madrid: Talasa Ediciones. 
Núñez Seixas, Xosé Manuel (2012): “El miedo al enemigo, o el extranjero como invasor (1936-1939)”, en N. Berthier e V. Sánchez-Biosca, Retóricas del miedo. Madrid: Casa de Velázquez, pp. 53-70.

Nussbaum, Marta (2014): Las emociones políticas ¿Por qué el amor es importante para la justicia? Barcelona: Paidós.

Pampler, Jam (2014): “Historia de las emociones: caminos y retos", Cuadernos de historia contemporánea 36, pp. 17-29.

Rueda, Juan Carlos (2018): Memoria roja. Una historia cultural de la memoria comunista en España, 1931-1977. Madrid: Taurus.

Ruiz Vargas, José María (2010): Manual de psicología de la memoria. Madrid: Síntesis.

Sánchez León, Pablo e Jesús Izquierdo Martín (2017): La guerra que nos han contado y la que no. Memoria e historia de 1936 para el siglo XXI. Madrid: Postmetrópolis.

Santidrián, Víctor (2018): "Enrique Líster: el antimilitarista que llegó a general”, Revista Universitaria de Historia Militar 7/13, pp. 423-439. 